\title{
Antidiabetic and Plasma Endogenous Antioxidant Activity of alstonia boonei in Alloxan-Induced Male Diabetic Rabbits
}

\section{*11OSADOLOR, HB; UKHUREIGBE, JI; OLANIYAN, OO}

\author{
Department of Medical Laboratory Science, School of Basic Medical Sciences, University of \\ Benin, P.M.B.1154, Benin City, Nigeria. \\ Department of Chemical Pathology, College of Health Sciences, Osun State University, Osogbo, Osun State. \\ Department of Medical Laboratory Science, School of Basic Medical Sciences, \\ University of Benin,; P.M.B.1154,Benin City, Nigeria \\ *Corresponding author Email: humphrey.osadolor@uniben.edu, +2347060813792, +2348023412768
}

\begin{abstract}
Alstonia boonei is a well-known plant of medicinal value but its effect on endogenous plasma antioxidant in diabetes remains unknown. Thus, need to investigate the effects of the methanolic extract of the plant on plasma bilirubin and uric acid level in alloxan induced diabetes rabbits. Twenty five rabbits divided into five groups of four rabbits each were used. There was a significant change in the levels of total bilirubin and uric acid in the plasma of treated groups as compared with both non-diabetes and untreated diabetes group, while conjugated bilirubin level was relatively unchanged in the treated group. This work clearly indicates that methanolic extract of Alstonia boonei stem bark is effective in the management of diabetes as well as restoration of lost endogenous plasma antioxidants experienced in diabetes mellitus. (C) JASEM
\end{abstract}

http://dx.doi.org/10.4314/jasem.v19i4.5

\begin{abstract}
Introduction
Diabetes mellitus is a metabolic disease that is as old as mankind; it is a major endocrine disorder and also a growing health problem globally (Pickup and Williams, 1997). Development of diabetes mellitus, course and its complications are closely associated with imbalance of pro- and antioxidative cell impairments and change of redox potentials (colak, et al., 2007), with concomitant increased production of free radicals and reduced capacity of antioxidant defence (Aronson and Rayfield, 2002). Diabetes mellitus accounts for over 4.8million annual deaths (9\% of global total) are attributed to either diabetes or its complications (Sunmonu and Afolayan, 2013).
\end{abstract}

Uric acid and bilirubin are part of the endogenous antioxidant defence mechanism present in the human system (Nag, et al., 2009, Ames, et al., 1981). Uric acid is the end product of purine metabolism, where purines by enzymatic hydrolytic deamination form xanthine and hypoxanthine compounds which are than oxidized to uric acid (White, et al., 2004). It is an important physiological antioxidant by providing a primary defence against oxidants based upon its capacity to scavenge singlet oxygen and its ability to inhibit lipid peroxidation (Bhargava, et al., 2015). Bilirubin, on the other hand is an end product of heme catabolism in mammals. It can effectively scavenge peroxyl radicals generated in a reaction (Stocker, et al., 1987). Serum uric acid levels had been shown to have an important role in the pathogenesis and progression of long term complications associated with diabetes mellitus (Ashakiran, et al., 2010). Likewise, circulating bilirubin is associated with decreased risk of type 2 diabetes, but the nature of the relationship remain unknown (Abbasi, et al., 2015).

Throughout the world, many cultures still rely on indigenous medicinal plants for their primary health care needs (Farnsworth, et al., 1985). The use of natural remedies for diabetes treatment is strengthened due to the belief that herbs can provide some benefits over allopathic medicine and allows users to feel that they have some control in their choice of medication. However, their general acceptability has been limited by lack of dose regimen and adequate data on their toxicity (Joshi and Kaul, 2004).

Alstonia boonei (De Wild) a genus of to the family Apocynaceae with about 40-60 species is a large deciduous evergreen tree, usually up to $45 \mathrm{~m}$ tall and $1.2 \mathrm{~m}$ in diameter (Owolabi, et al., 2014, Akinloye, et al., 2013). The plant is commonly being sold in the local markets of West and Central Africa and used for ameliorating some disease conditions (Bello, et al., 2009) however, to the best of our knowledge, there is limited information on the effect of this plant on diabetes mellitus. In an attempt to carry out 
further scientific scrutiny on this plant, this study aims at investigating possible hypoglyceamic and the corresponding effects of the methanolic extracts of A.boonei on plasma uric acid and bilirubin levels of alloxan induced rabbits.

\section{MATERIALS AND MEHODS}

Animals: Adult rabbits weighing between $1-2 \mathrm{~kg}$ were obtained from the Animal House of the Faculty of life Sciences, University of Benin, Benin City. The animals were acclimatised for fourteen (14) days in well ventilated animal cages under good hygienic and standard environmental conditions, with 12 hours of light/dark cycle and were maintained on a regular feed (vital feed) and water ad libitum.

Collection and preparation of methanolic extracts: The stem bark, leaves and root of A. Boonei were collected around the premises of the University of Benin, Benin city, between June and July 2014. The plant was authenticated by Dr. Akinibosun, A.O. of the Department of Plant Biology and Biotechnology, University of Benin, Benin city, Edo State, Nigeria.

Plant parts of $A$. boonei were ensured to be free of debris by washing and air-dried at room temperature for 7 days. The plant parts were then pulverized into powder, using commercial blender and the powdered plant parts were stored in different air-tight containers prior to extraction.

$2 \mathrm{~kg}$ each of the pulverized plant parts were weighed and transferred into different containers. 4.0 litres of methanol was added to each container containing the stem bark, leaf and root powder. They were thoroughly mixed and allowed to stand for 24 hours. They were shaken at intervals to ensure thorough extraction. The macerated extract was filtered with a cheese cloth and the filtrates concentrated to dryness in a water bath set at 40 degree centigrade. The extracts were reconstituted prior to administration using normal saline. $100 \mathrm{mg}$ per kilogram of body weight of extracts (stem bark, leaf and root) was administered orally to the rabbits once daily (in the morning) for a period of seven (7) days.

Induction of experimental diabetes Diabetes mellitus was induced in sixteen rabbits according to the method of Katsumata, et al., (1993). The animals were allowed to fast overnight. The alloxanmomohydrate was injected intravenously (through the marginal ear vein) in a $12 \mathrm{hrs}$ fasted rabbits at a dose of $100 \mathrm{mg} / \mathrm{kg}$ body weight. Each $100 \mathrm{mg}$ of alloxan-momohydrate was diluted in $1 \mathrm{ml}$ of physiological saline. $10 \mathrm{ml}$ of $20 \%$ glucose D solution was injected to each rabbit immediately after induction of alloxan monohydrate in order to overcome sudden decrease in the animal blood glucose level. Diabetes was confirmed ten (10) days later, glucose level greater than $200 \mathrm{mg} / \mathrm{dl}$ were considered as diabetic (Enechi, et.al., 2014). Baseline fasting blood glucose levels and diabetes status determination was monitored on blood obtained from the marginal ear vein puncture using an automated glucose sensor machine Glucometer Analyser (Accu Chek Active).

Experimental protocol/design: A total of thirty twenty five (25) rabbits were divided into five (5) groups of four (4) rabbits each. The animals were grouped as follows: Group 1: (Reference/Normal control): Rabbits were fed with normal diet and water ad libitum, neither alloxan nor plant extract was administered. Group 2: This is the positive control group. Alloxan was administered to the animals in this group. No plant extract was administered. Group 3: Rabbits received root extract along feeds and water for seven days, alloxan was also administered Group 4: Rabbits received leaf extract along feeds and water for seven days, alloxan was also administered Group 5: Rabbits received stem bark extracts along feeds and water for seven days, alloxan was also administered

Collection and processing of blood and tissue samples: On the day of sacrifice, food and water were withdrawn 6 hours prior to the time of sacrifice. This was done to minimize the glycogen stored in the body. The animals were sacrificed under chloroform anaesthesia, blood samples were collected using $5 \mathrm{ml}$ syringes from the abdominal aorta and left ventricle of the heart. The blood samples were introduced into lithium heparinized bottles and then mixed properly by gentle inversion. The blood samples were centrifuged at 4000 revolution per minute for 10 minutes. The resulting plasma were collected into plain sterile bottles and stored at $-20^{\circ} \mathrm{C}$ until analyses. Uric acid was estimated by phosphotungstate technique while total and conjugated bilirubin in plasma was estimated by the methods of Jendrasik and Grof (Sood, et al., 2006).

Statistical analysis: Data generated were evaluated using Statistical Package for Social Sciences program (SPSS) version 16.0. Values were expressed as mean $( \pm \mathrm{SD})$. The difference between the mean were analysed statistically with one way analysis of variance (ANOVA; 95\% confidence interval), followed by Duncan Multiple Range Test. Values of $\mathrm{p}<0.05$ were considered statistically significant. 


\section{RESULTS AND DISCUSSION}

It was observed that all the rabbits that were not induced with alloxan-monohydrate moved freely throughout the period of experimentation while, the diabetic rabbits both treated and untreated appeared sluggish and highly lethargic. The blood glucose level of diabetic rabbits was significantly $(\mathrm{p}<0.05)$ higher than that of other groups and was also accompanied by significant reduced body weight. The mean blood glucose concentrations of all the rabbits in each experimental group are shown in table 1. There is also a non-significant $(p>0.05)$ high concentration of plasma uric acid in untreated diabetes rabbits when compared to non-diabetes rabbits. This uric acid concentration is reversed in treated diabetes rabbits with stem bark extract exerting the most significant $(\mathrm{p}<0.05)$ effect. However, total bilirubin from our study revealed a significant $(p<0.05)$ increase in untreated diabetes rabbits when compared with non-diabetes rabbits, with stem bark extract exerting the most significant $(p<0.05)$ effect while, conjugated bilirubin did not show any significant $(\mathrm{p}>0.05)$ effect.

Table 1: Concentrations of blood glucose, plasma uric acid and bilirubin in controls and experimental Rabbits

\begin{tabular}{|c|c|c|c|c|c|c|c|c|}
\hline Groups & & & & & & & & \\
\hline Parameters & 1 & & 2 & & 3 & & 4 & 5 \\
\hline Gluc & & $65.5 \pm 5.6_{a}$ & $316.9 \pm 28.4_{b}$ & $244.4 \pm 29.6_{c}$ & $295.9 \pm 12.7 \mathrm{~d}$ & $199.6 \pm 32.8_{\mathrm{e}}$ & & \\
\hline UA & & $\begin{array}{ll}2.07 & \pm \\
0.56_{a} & \end{array}$ & $1.8 \pm 0.13_{b}$ & $2.3 \pm 0.40_{c}$ & $2.53 \pm 0.34_{d}$ & $3.18 \pm 0.45_{a}$ & & \\
\hline TB & & $\begin{array}{ll}0.35 & \pm \\
0.10_{a} & \end{array}$ & $2.10 \pm 0.13_{b}$ & $0.55 \pm 0.06_{c}$ & $1.83 \pm 0.17_{\mathrm{d}}$ & $0.11 \pm 0.01_{\mathrm{e}}$ & & \\
\hline CB & & $\begin{array}{l}0.05 \\
0.10_{\mathrm{a}}\end{array}$ & $0.06 \pm 0.02 \mathrm{a}$ & $0.12 \pm 0.04_{a}$ & $0.09 \pm 0.02_{\mathrm{a}}$ & $0.06 \pm 0.01 \mathrm{a}$ & & \\
\hline
\end{tabular}

Values with different subscript along the same row are significantly different at $\mathrm{p}<0.05$.

Gluc $=$ Glucose, $\mathrm{UA}=$ Uric acid, $\mathrm{TB}=$ Total Bilirubin $\mathrm{CB}=$ Conjugated Bilirubin

Hyperglycemia, a major feature of diabetes mellitus generates oxidative stress, which is exacerbated by metabolic stress (Dave, et al., 2015). Our present study therefore, investigated the antidiabetic activities of methanolic extracts of $A$. boonei and its effects on plasma endogenous antioxidants of bilirubin and uric acid in diabetes induced rabbits.

The methanol extracts of A.boonei from our study lowered the rabbit blood glucose level effectively, with the stem bark extract producing the most significant effects. A result that support the earlier work on A.boonei by Owolabi, et al., (2014) and Akinloye, et al., (2013), This antidiabetic effect though un-established may have produced hypoglycaemic action by being insulinomimetic (Owolabi, et al., 2014) or by stimulating glucose catabolising enzymes and inhibiting gluconeogenic enzymes (Akinloye, et al., 2013).

Bilirubin, a strong antioxidant and anti-inflammatory compound exerts its action on vasculature, thereby acting as a cytoprotectant to the vasculature (Stocker, et al., 1987, Cho, 2011). It also scavenges lipid peroxides and other products of physiological oxidation (Ramesh, et al., 2015). Serum bilirubin levels have been proven to be associated with microalbuminuria and sub clinical atherosclerosis in patients with type 2 diabetes (Fukui, et al., 2008), this present study however, showed that only total bilirubin and not conjugated bilirubin has a significant increase in the plasma of untreated diabetes rabbits when compared to non-diabetes rabbits, suggesting a response of the animal body system to oxidative stress caused by diabetes by way of producing of more bilirubin to mop-up the oxidants in the animal system as bilirubin may compensate the oxidative stress which might be an important factor in the pathophysiology of diabetes (). Increased level of bilirubin had been shown by Fu, et al., (2010) and Dong, et al., (2014) to reduced streptozotocin-induced pancreatic beta-cells damage in mice by attenuating oxidative stress and increasing insulin sensitivity respectively. An investigation on the effects of the extracts on plasma bilirubin in diabetes induced rabbits also revealed that all the extracts have potentials of reversing the hyperbilirubineamia with stem bark exerting the most significant effects.

Uric acid is involved in a complex reaction with several oxidants and may have some protective effects under certain conditions (Sautin and Johnson 2008). It is an antioxidant in the extracellular environment, reacting with superoxide (to make allantoin) and with peroxynitrite (to make triuret). These antioxidant properties of uric acid were proposed to be beneficial by protecting against ageing and associated oxidative stress (Ames, et al., 1981). The uric acid concentration in the body of our diabetes induced animals shows a non significant low level when compared to non-diabetes animals, a 
feature that is different from earlier reported work of Cooke, et al., (1986) and Safi, et al., that reported hyperuricaemia in body of diabetes human. It was also observed that stem bark extract produced the most significant increased level of uric acid in the body of our treated diabetes animals. We therefore proposed that the reduced level may be due to oxidative stress experienced in diabetes condition.

Conclusion: This study has clearly revealed that methanolic stem bark extract of Alstonia boonei is an effective antidiabetic agent that can be of help in the treatment of diabetes mellitus and restoration of the lost endogenous antioxidant activities of both plasma uric acid and bilirubin concentrations. More work needs to be done on the effect of the plant extract on both enzymatic and non enzymatic antioxidant mechanism in the management of diabetes using large pool of animals.

\section{REFERENCES}

Akinloye, O.A., Oshilaja, R.T., Okelanfa O.A., Akinloye, D.I and Idowu, O.M.O. (2013). Hypoglyceamic activity of Alstonia boonei stem bark extract in mice. Agric. Biol. J. N. Am (4) $1: 1-5$.

Ames, B.N., Cathacart, R., Schwiers, E and Hochstein, P. (1981).Uric acid provides an antioxidant defense in humans against oxidantand radical-caused aging and cancer: a hypothesis. Proc Natl Acad Sci USA 78(11):6858-6862.

Aronson, D. and Rayfield, E.J. (2002). How hyperglycemia promotes atherosclerosis: molecular mechanisms. Cardiovascular Diabetology 1:1.

Ashakiran, S., Krishnamurthy, N., Navin, S. And Patil, S. (2010). Behaviour of serum uric acid and lipid profile in relation to glycemic status in proliferative and non-proliferative diabetic retinopathy. Current Neurobiology 2(1):57-61.

Bello, I.S., Oduola, T., Adeosun, O.G., Omisore, N.O.A., Raheem, G.O.and Ademosun, A.A. (2009). Evaluation of antimalarial activity of various fractions of Morinda lucinda leaf extract and Alstonia boonei stem bark. Glob. J. Pharmocol. 3(3):163-165.

Bhargava, A.K., Diwan, R., Mathur, M. and Bohra V.D. (2015). Analysis of serum uric acid and bilirubin in breast cancer. International Journal of Scientific Research (IJSR) 4(2):272-273.
Bilirubin as a potential causal factor in type 2 diabetes risk: a Mendelian randomization study. Abbasi, A., Deetman, P.E., Corpeleijn, E., Gansevoort, R.T., Gans, R.O.B., Hillege, H.L., Harst, P.V., Stolk , R.P., Navis , G., Alizadeh, B.Z. and Stephan J.L. Bakker S.J.L. (2015). Diabetes 64(4):1459-1469.

Cho, H.C. (2011) The relationship among homocysteine, bilirubin, and diabetic retinopathy. Diabetes Metab J 35:595-601.

Čolak, E., Dimitrijević-Srećković, V., Djordjević, P.B., Stanković, S., Glišić, B., Srećković, B. and Majkić-Singh, N. (2008). Biomarkers of enzymatic and non-enzymatic antioxidative defense in type 2 diabetes mellitus-comparative analysis. Biochemia Medica.18(2):42-51.

Cook, D.G., Shaper, A.G., Thelle, D.S. and Whitehead, T.P. (1986). Serum uric acid, serum glucose and diabetes: relationship in a population study. Postgraduate Medical Journal 62:10011006.

Dave, A., Kalra, P, Gowda, B.H. R. and Krishnaswamy, M. (2015). Association of bilirubin and malondialdehyde levels with retinopathy in type 2 diabetes mellitus. Indian Journal of Endocrinology and Metabolism 19(3):373-377.

Dong, H., Huang, H., Yun, X., Kim, D.S., Yue, Y., Wu, H., Sutter, A., Chavin, K.D., Otterbein, L.E., Adams, D.B., Kim, Y.B and Wang, H. (2014). Bilirubin increases insulin sensitivity in leptin-receptor deficient and diet- induced obese mice through suppression of ER stress and chronic inflammation. Endocrinology. 155:818828.

Enechi, O.C., Oluka, I.H. and Ugwu, O.P.C. (2014). Acute toxicity, lipid peroxidation and ameliorative properties of Alstonia boonei ethanol leaf extract on the kidney markers of alloxan induced diabetic rats. Afr. J. Biotechnol (13)5:678-682.

Farnsworth, N., Akerele, A.O., Bingel, A.S., Soejarto, D.D. and Guo, Z. (1985). Medicinal plants in therapy. Bull. WHO. 63(6):965-981.

Fu, Y.Y., Kang, K.J., Ahn, J.M., Kim, H.R., Na, K.Y., Chae, D.W., Kim, S. and Chin, H.J. (2010). Hyperbilirubinemia reduces the streptozotocin-induced pancreatic damage 
through attenuating the oxidative stress in the Gunn rat. Tohoku J Exp Med. 222:265-273.

Fukui M, Tanaka M, Shiraishi E, Harusato I, Hosoda H, Asano M. (2008). Relationship between serum bilirubin and albuminuria in patients with type 2 diabetes. Kidney Int 74:1197-201.

Joshi, B.S and Kaul, P.N. (2001). Alternative medicine: herbal drugs and their critical appraisal-part I,"Progress in Drug Research (56): $1-76$.

Katsumata K, Katsumata Y, Ozawa $\mathrm{T}$ and Katsumata Jr. (1993). Potentiating effect of combined usage of three sulfonylurea drugs on the occurrence of alloxan diabetes in rats. Horm Metab Res 25:125-126.

Nag, N., Halder, S., Chaudhuri, R., Adhikary, S and Mazumder, S. (2009). Role of Bilirubin as antioxidant in neonatal jaundice and the effect of ethanolic extract of sweet lime peel on experimentally induced jaundice in rat. Indian $J$ Biochem Biophys 46(1):73-8.

Owolabi, O.J., Arhewoh, I.M., Innih, S.O., Anaka, O.N4 and Monyei, C. F. (2014).The ethanol leaf extract of alstonia boonei (apocynaceae) reduces hyperglycemia in alloxan-induced diabetic rats. Nig. Journ. Pharm. Sci. (13)1:12-21.

Pickup, J.C. and Williams, G. (1997). Epidemiology of Diabetes mellitus. Blackwell, Oxford, UK.
Ramesh, R., AdhishwarKumaran, N., KuzhandaiVelu, V., Reeta, R., SathishBabu, M. and Niranjan, G. (2015). Association between Hepato-Biliary Status and HbA1C in Type 2 Diabetes Mellitus with Coronary Artery Disease (CAD). Journal of Diabetes Mellitus 5:67-71.

Sautin, Y.Y and Johnson, R.J. (2008). Uric acid: the oxidant-antioxidant paradox. Nucleosides Nucleotides Nucleic acids 27(6):608-19

Sood, R. (2006). Clinical Chemistry in Medical laboratory technology: Methods and Interpretations. 5th Ed. Jaypee Brothers Medical Publishers (P) Ltd. New Delhi. pp 378-479. Stocker, R., Yamamoto, Y., McDonagh, A.F., Glazer, A.N. and Ames, B.N. (1987). Bilirubin is an antioxidant of possible physiological importance. Science 235:1043-6.

Sunmonu, T.O. and Afolayan, A.J. (2013). Evaluation of antidiabetic activity and associated toxicity of Artemisia afra aqueous extract in wistar rats. Evidence-based_Complementary and Alternative Medicine. http://dx.doi.org/10.1155/2013/929074 Retrieved $\underline{01 / 09 / 2015 .}$.

White, A., Handler, P., Smith, E. L., Hill, R. L. and Lehman, R. L. (2004). Principles of Biochemistry 6th Ed. Tata Mc Graw Hill Publishing Company Limited, New Delhi. 